\title{
A comparative profile analysis of neuropsychological function in men and women with schizotypal personality disorder
}

\section{Citation}

VOGLMAIER, M, L SEIDMAN, M NIZNIKIEWICZ, C DICKEY, M SHENTON, and R MCCARLEY. 2005. A Comparative Profile Analysis of Neuropsychological Function in Men and Women with Schizotypal Personality Disorder. Schizophrenia Research 74, no. 1: 43-49. doi:10.1016/ j.schres.2004.09.013.

\section{Published Version}

doi:10.1016/j.schres.2004.09.013

\section{Permanent link}

http://nrs.harvard.edu/urn-3:HUL.InstRepos:33766569

\section{Terms of Use}

This article was downloaded from Harvard University's DASH repository, and is made available under the terms and conditions applicable to Other Posted Material, as set forth at http:// nrs.harvard.edu/urn-3:HUL.InstRepos:dash.current.terms-of-use\#LAA

\section{Share Your Story}

The Harvard community has made this article openly available.

Please share how this access benefits you. Submit a story.

Accessibility 


\title{
A comparative profile analysis of neuropsychological function in men and women with schizotypal personality disorder
}

\author{
Martina M. VogImaier ${ }^{*}$, Larry J. Seidman, Margaret A. Niznikiewicz, Chandlee C. Dickey, \\ Martha E. Shenton, and Robert W. McCarley \\ Harvard Medical School, Department of Psychiatry at the Massachusetts Mental Health Center, \\ Boston, MA, United States, Brockton/West Roxbury Veterans Affairs Medical Center, Brockton, MA, \\ United States, Cambridge Health Alliance, Cambridge, MA, United States
}

\begin{abstract}
The purpose of this study was to compare the cognitive profiles of men and women with clinically defined schizotypal personality disorder (SPD). We examined the neuropsychological profile of SPD in 26 right-handed females and 31 right-handed males who met DSM-IV criteria for SPD, and matched comparison subjects. Cognitive performance was assessed on measures of abstraction, verbal and spatial intelligence, learning and memory, language, attention, and motor skills. Neuropsychological profiles were constructed by standardizing test scores based on the means and standard deviations of comparison groups matched for sex, age, handedness, ethnicity and parental SES. Overall, SPD subjects showed mild, general decrements in performance in most cognitive domains. However, unlike male SPD subjects, female SPDs did not show relative deficits in verbal learning and abstraction. The results suggest a less severe pattern of cognitive deficits in women with SPD compared to men, consistent with hypotheses of gender differences in cognitive function in schizophrenia.
\end{abstract}

\section{Keywords}

Schizotypal personality disorder; Neuropsychological dysfunction; Gender differences; Abstraction; Frontal networks; Temporolimbic systems

\section{Introduction}

Studies of gender differences in schizophrenia indicate a less severe form of the disorder in females, who tend to exhibit later age of disease onset, better premorbid history, more positive and fewer negative symptoms, fewer structural brain abnormalities and a better response to neuroleptic medications (e.g., Tamminga, 1997; Goldstein and Levine, 2000). Some studies addressing neuropsychological performance in schizophrenia suggest that women exhibit less severe cognitive deficits than men (Seidman et al., 1997; Goldstein et al., 1998), although not all studies are consistent with this observation (e.g., Lewine et al., 1996; Albus et al., 1997). The putative sex differences in cognitive function have been variously explained as a function

\footnotetext{
Supported by the Medical Research Service of the Department of Veterans Affairs (RWM), NIMH 1-R01-MH52807 (RWM), NIMH RO1 40,779 (RWM), NIMH KO2-MH-0110 (MES), NIMH MH-R29 50747 (MES), Peter Livingston Research Fellowship (MMV) and Research and Education Fund Fellowship (MMV) from the Department of Psychiatry, Harvard Medical School, Massachusetts Mental Health Center.

(C) 2004 Elsevier B.V. All rights reserved.

*Corresponding author. Department of Psychiatry, Cambridge Health Alliance, 1493 Cambridge St., Cambridge, MA 02139, United States. Tel.: +1 617665 2169; fax: +1 617665 1149, martina_voglmaier@hms.harvard.edu (M.M. Voglmaier).
} 
of the normal sexual dimorphism of the brain or the modulating effects of estrogen on dopamine systems (Lindamer et al., 1997; Goldstein et al., 2002).

Schizotypal personality disorder (SPD) is characterized by oddities in appearance, perception and behavior that appear to represent a milder variant of schizophrenia (Kety et al., 1975). We previously studied a wide range of cognitive functions in a small group of men who met full diagnostic criteria for SPD, and found significant deficits on measures of verbal learning and abstraction (Voglmaier et al., 1997). This profile was similar to that found in patients with schizophrenia, albeit less severe, and we suggested it might reflect similar involvement of frontal and left temporal brain areas. Because our previous sample was limited to men, it was unclear if this profile was representative of cognitive function in women with SPD.

Gender differences in clinical, biological and cognitive profiles have not been studied in clinically defined SPD. Some studies have identified cognitive deficits in mixed groups of male and female SPD subjects (e.g., Cadenhead et al., 1999). Others have shown gender differences in cognitive function associated with schizotypal symptoms in healthy college students (e.g., Lubow et al., 2001; Lubow and De la Casa, 2002; Gruzelier, 1994), although the relationship of these symptoms to clinically defined SPD and schizophrenia remains unclear. The purpose of the current study was to compare the cognitive profiles of men and women with DSM-IVdefined SPD. We hypothesized: (1) that females with SPD would be impaired relative to female controls, and (2) that sex differences in SPD would be similar to those in schizophrenic subjects, in that females with SPD would have less severe cognitive deficits than males.

\section{Experimental materials and methods}

\subsection{Subjects}

Subjects were 26 right-handed women and 31 right-handed men who met DSM-IV criteria for SPD; the groups were compared to 24 right-handed female and 23 right-handed male control subjects, respectively, who were comparable on age, ethnicity and parental socioeconomic status. Recruitment and diagnostic procedures have been described elsewhere (Voglmaier et al., 1997). Briefly, SPD subjects met full clinical diagnostic criteria based on structured clinical interview. They had no lifetime history of Axis I bipolar or psychotic disorder, and no current depressive disorder. There was considerable diagnostic overlap with other Axis II personality disorders, in accord with other reports (Oldham et al., 1992). All but three male SPD subjects, and all but four female SPD subjects, had at least one other personality disorder diagnosis. Control subjects had no lifetime history of Axis I or Axis II disorder. After complete description of the study to the subjects, written informed consent was obtained. All subjects were paid for their participation in the study.

\subsection{Data analysis}

Mann-Whitney $U$-tests for independent samples were employed to examine demographic variables (see Table 1). The female SPD and control groups did not differ in age, parental SES, or estimated IQ. Female SPDs had significantly less education and lower personal SES than female comparisons. The male SPD and comparison groups did not differ in age, education, or parental SES. Male SPDs had significantly lower estimated IQ and personal SES and significantly more symptoms of depression than male control subjects. As in our previous work, because of concerns about appropriate matching of groups on indices that may be reduced as a result of schizophrenia spectrum disorder (Voglmaier et al., 1997,2000), we chose to separately calculate a verbal IQ estimate based on the WAIS-R Vocabulary subtest and a nonverbal estimate of general ability based on the WAIS-R Block Design subtest. Among males, the difference in estimated IQ was due to reduced performance on the WAIS-R 
Vocabulary subtest. There was no significant difference between the groups on the nonverbal IQ measure.

The neuropsychological domains included abstraction, verbal and spatial intelligence, memory and learning, language, attention and motor skills (see Table 2), and are described in detail in our previous work (Voglmaier et al., 1997). SPD subjects' test scores were standardized based on the means and standard deviations of their respective comparison group. This procedure helps to control for differences in psychometric properties (e.g., reliability, difficulty) of tests across domains (Chapman and Chapman, 1989), and has been employed previously by our group and others (Saykin et al., 1991;Goldstein et al., 1998). Repeated-measures analyses of variance (ANOVAs, multivariate option) with neuropsychological domains or test scores as the dependent variables and subject group (male vs. female) as the independent variable were used to assess differences between groups and profile shapes. This was followed by withinsubject contrasts on each domain for determination of areas of selective deficit, and betweensubject contrasts to determine cognitive differences related to gender. For each contrast, the standardized score for a particular function was contrasted with the mean of all functions (SPSS/PC 11.5, contrast procedure, deviation option). This allowed for determination of areas of selective deficit, as opposed to general impairment equally affecting all functions. VIQ (based on WAIS-R Vocabulary subtest raw score), education and BDI scores, those scores that differed between the groups, were used as covariates in separate analyses to correct for their effects. Because the covariate analyses included only standardized scores for each cognitive domain, the Verbal Intelligence Domain (including the WAIS-R Vocabulary subtest) remained in the analyses when VIQ was covaried.

\section{Results}

The $z$-score profile of neuropsychological functioning is presented in Fig. 1. Female and male SPDs are contrasted relative to their respective comparison groups, which are set to zero $( \pm 1$ S.D.). The MANOVA revealed a significant main effect for Cognitive Domain $[F(6,37)$ $=44.74, p<0.001]$, a non-significant trend for Group $[F(1,42)=8.94, p=0.072)$, and a significant Group $\times$ Domain interaction $[F(21,242)=2.16, p<0.01]$, indicating different profile shapes for male and female SPD groups. Among males, within-subject contrasts revealed significant deficits in the domains of abstraction, verbal intelligence and verbal learning $(p<0.05)$. Among females, only verbal intelligence was an area of selective impairment $(p<0.05)$. When verbal IQ, education and Beck Depression Inventory (BDI; Beck, 1978) scores were added as covariates, female SPD subjects did not show areas of selective cognitive deficit. Male SPD subjects showed relative deficits in the domains of verbal learning and abstraction, and between-group contrasts revealed significantly lower performance in verbal learning compared to females $(p<0.05)$. Differences between the groups in other neuropsychological functions were not significant.

\section{Discussion}

To our knowledge, this is the first study to compare the neuropsychological profiles of clinically defined SPD in women and men. As hypothesized, the results indicate that female SPD subjects show a mild, general reduction in neuropsychological performance compared to female comparison subjects. The profile in female SPD also indicates less severe cognitive impairment than in male SPD subjects, consistent with previous studies of gender differences in schizophrenia. The female SPD profile differs from that of male SPD subjects, where abstraction and verbal learning were specific areas of deficit against a background of mild, general reductions in most cognitive domains. It is noteworthy that no areas of selective cognitive deficit were evident in the female SPD profile after education, VIQ and BDI scores were covaried from the analyses. This underscores the importance of assessing comorbid mood 
symptomatology in schizotypal research (e.g., Spitznagel and Suhr, 2004), and suggests that symptoms of depression may have a particular impact on cognitive function in female SPD.

\subsection{Gender differences}

The primary difference in cognitive performance between male and female SPDs appears to be in verbal learning, where females' performance was relatively normal, and males' performance was more comparable to schizophrenic subjects (Goldberg et al., 1990). It is noteworthy that the verbal learning deficit was apparent in males with SPD even after a stringent matching procedure equating the groups on general verbal ability. These findings are in accord with Goldstein et al. (1998) who suggested that female schizophrenics may be less vulnerable to verbal processing deficits than males.

\subsection{Neuropsychology of SPD}

The neuropsychology of SPD may be understood within the context of hypotheses that schizophrenia involves deficits in a highly interconnected neural system involving dorsolateral prefrontal and temporal lobe structures. Within such a framework, cognitive deficits could reflect dysfunction at any one or more points within the system and vary accordingly. For example, in schizophrenic patients, poor performance on the WCST has been related to dorsolateral prefrontal lobe dysfunction (Weinberger, 1987, 1991; Seidman et al., 1994; Weinberger et al., 1992), and category formation on this task has been associated with gray matter volume reduction in temporal lobe regions (Nestor et al., 1993). In SPD, brain imaging studies have revealed abnormalities in temporal and prefrontal areas (Dickey et al., 1999; Buchsbaum et al., 2002).

In conclusion, these results suggest that females with SPD tend to show less severe cognitive deficits overall than males, and do not exhibit the deficits in verbal learning seen in male SPDs. The results underscore the cognitive deficits and treatment needs of SPD individuals, and suggest that these may differ according to gender. Difficulties in social and occupational performance in this group may stem from both characterological features and cognitive deficits. Selected primarily from the general population, our SPD groups had at least average intelligence and came from middle class families, yet personal SES was lower than parental SES. Further study of the behavioral, functional, and structural correlates of brain function in SPD populations is warranted to examine the cognitive and clinical features of this disorder, as well as to help shape our understanding of the pathophysiology of schizotypy and schizophrenia.

\section{Acknowledgments}

The authors wish to thank Anita Madan, Richard Rhoads, Jonathan Sutton and EngKeat Teh for assistance with this study.

\section{References}

Albus M, Hubmann W, Mohr F, Scherer J, Sobizack N, Franz U, Hecht S, Borrmann M, Waldheim C. Are there gender differences in neuropsychological performance in patients with first-episode schizophrenia. Schizophr. Res 1997;28:39-50. [PubMed: 9428063]

Beck, AT. Center for Cognitive Therapy. Philadelphia: 1978. The Beck Depression Inventory.

Benton, AL.; Hamsher, KdeS. Multilingual Aphasia Examination. Iowa City: University of Iowa; 1976.

Brooker BH, Cyr JJ. Tables for clinicians to use to convert WAIS-R short forms. J. Clin. Psychol 1986;42:983-986.

Buchsbaum MS, Nenadic I, Hazlett EA, Spiegel-Cohen J, Fleischman MB, Akhavan A, Silverman JM, Siever LJ. Differential metabolic rates in prefrontal and temporal Brodmann areas in schizophrenia and schizotypal personality disorder. Schizophr. Res 2002;54:141-150. [PubMed: 11853988] 
Cadenhead KS, Perry W, Shafer K, Braff DL. Cognitive functions in schizotypal personality disorder. Schizophr. Res 1999;37:123-132. [PubMed: 10374648]

Chapman LJ, Chapman JP. Strategies for resolving the heterogeneity of schizophrenics and their relatives using cognitive measures. J. Abnorm. Psychology 1989;98:357-366.

Delis, DC.; Kramer, JH.; Kaplan, E.; Ober, BA. California Verbal Learning Test Manual—Research Edition. San Diego: The Psychological Corporation; 1987.

Dickey CC, McCarley RW, Voglmaier MM, Niznikiewicz MA, Seidman LJ, Hirayasu Y, Fischer I, Teh E, Rhoads R, Jakab M, Kikinis R, Jolesz FA, Shenton ME. Schizotypal personality disorder and MRI abnormalities of temporal lobe gray matter. Biol. Psychiatry 1999;45:1393-1402. [PubMed: 10356620]

Goldberg TE, Ragland D, Fuller Torrey E, Gold JM, Bigelow L, Weinberger DR. Neuropsychological assessment of monozygotic twins discordant for schizophrenia. Arch. Gen. Psychiatry 1990;47:1066-1072. [PubMed: 2241508]

Goldstein, JM.; Levine, RRJ. Overview of sex differences in schizophrenia: where have we been and where are we do we go from here? In: Castle, DJ.; McGrath, JJ.; Kulkarni, J., editors. Women and Schizophrenia. Cambridge, MA: Cambridge University Press; 2000. p. 111-153.

Goldstein JM, Seidman LJ, Goodman JM, Koren D, Lee H, Weintraub S, Tsuang MT. Are there sex differences in neuropsychological functions among patients with schizophrenia? Am. J. Psychiatry 1998;155:1358-1364. [PubMed: 9766767]

Goldstein JM, Seidman LJ, O’Brien LM, Horton NJ, Kennedy DN, Makris N, Caviness VS, Faraone SV, Tsuang MT. Impact of normal sexual dimorphisms on sex differences in structural brain abnormalities in schizophrenia assessed by magnetic resonance imaging. Arch. Gen. Psychiatry 2002;59:154-164. [PubMed: 11825137]

Goodglass, H.; Kaplan, E. The Assessment of Aphasia and Related Disorders. Vol. 2nd ed.. Philadelphia: Lea and Febiger; 1983.

Gruzelier JH. Syndromes of schizophrenia and schizotypy, hemispheric imbalance and sex differences: implications for developmental psychopathology. Int. J. Psychophysiol 1994;18:167-178. [PubMed: 7775214]

Heaton, RK. Wisconsin Card Sorting Test, Manual. Odessa, FL: Psychological Assessment Resources; 1981.

Kety, SS.; Rosenthal, D.; Wender, PH., et al. Mental Illness in the biological and adoptive families of adopted individuals who have become schizophrenic: preliminary report based on psychiatric interviews. In: Fieve, RR.; Rosenthal, D.; Brill, H.; Baltimore, MD., editors. Genetic Research in Psychiatry. Johns Hopkins University Press; 1975. p. 147-165.

Lewine RR, Walker EF, Shurett R, Candle J, Haden C. Sex differences in neuropsychological functioning among schizophrenic patients. Am. J. Psychiatry 1996;153:1178-1184. [PubMed: 8780422]

Lindamer LA, Lohr JB, Harris MJ, Jeste DV. Gender, estrogen and schizophrenia. Psychopharmacol. Bull 1997;33(2):221-228. [PubMed: 9230634]

Lubow RE, De la Casa G. Latent inhibition as a function of schizotypality and gender: implications for schizophrenia. Biol. Psychol 2002;59:69-86. [PubMed: 11790444]

Lubow RE, Kaplan O, De la Casa G. Performance on visual search analog of latent inhibition is modulated by an interaction between schizotypy and gender 2001. Schizophr. Res 2001;52:275-287. [PubMed: 11705721]

Nestor PG, Shenton ME, McCarley RW, Haimson J, Smith RS, O’Donnell B, Kimble M, Kikinis R, Jolesz FA. Neuropsychological correlates of MRI temporal lobe abnormalities in schizophrenia. Am. J. Psychiatry 1993;150(12):1849-1855. [PubMed: 8238641]

Oldham JM, Skodol AE, Kellman HD, Hyler SE, Rosnick L, Davies M. Diagnosis of DSM-IIIR personality disorders by two structured interviews: patterns of comorbidity. Am. J. Psychiatry 1992;149:213-220. [PubMed: 1734742]

Reitan, RM.; Wolfson, D. The Halstead-Reitan Neuropsychological Test Battery: Theory and Clinical Interpretation. Tucson, AZ: Neuropsychology Press; 1985.

Saykin AJ, Gur RC, Gur RE, Mozley D, Mozley LH, Resnick SM, Kester B, Stafiniak P. Neuropsychological function in schizophrenia: selective impairment in memory and learning. Arch. Gen. Psychiatry 1991;48:618-624. [PubMed: 2069492] 
Seidman LJ, Yurgelun-Todd D, Kremen WS, Woods BT, Goldstein JM, Faraone SV, Tsuang MT. Relationship of prefrontal and temporal lobe MRI measures to neuropsychological performance in chronic schizophrenia. Biol. Psychiatry 1994;35:235-246. [PubMed: 8186328]

Seidman LJ, Goldstein JM, Goodman JM, Koren D, Turner WM, Faraone SV, Tsuang MT. Sex differences in olfactory identification and Wisconsin card sorting performance in schizophrenia: relationship to attention and verbal ability. Biol. Psychiatry 1997;42(2):104-115. [PubMed: 9209727]

Spitznagel MB, Suhr JA. Neuropsychological impairment associated with symptoms of schizotypy: role of depressive and paranoid symptoms. J. Nerv. Ment. Dis 2004;192:382-384. [PubMed: 15126893]

Tamminga CA. Gender and schizophrenia. J. Clin. Psychiatry 1997;58:33-37. [PubMed: 9427875]

Voglmaier MM, Seidman LJ, Salisbury D, McCarley RW. Neuropsychological dysfunction in schizotypal personality disorder: a profile analysis. Biol. Psychiatry 1997;41:530-540. [PubMed: 9046985]

Voglmaier MM, Seidman LJ, Niznikiewicz MA, Dickey CC, Shenton ME, McCarley RW. Verbal and nonverbal neuropsychological test performance in subjects with schizotypal personality disorder. Am. J. Psychiatry 2000;157:787-793. [PubMed: 10784473]

Wechsler, D. Wechsler Adult Intelligence Scale-Revised, Manual. Cleveland: The Psychological Corporation; 1981.

Weinberger DR. Implications of normal brain development for the pathogenesis of schizophrenia. Arch. Gen. Psychiatry 1987;44:660-670. [PubMed: 3606332]

Weinberger, DR. Anteromedial temporal-prefrontal connectivity: a functional neuroanatomical network implicated in schizophrenia. In: Carroll, BJ.; Barrett, JE., editors. Psychopathology and the Brain. New York: Raven Press; 1991.

Weinberger DR, Berman KF, Suddath R, Torrey EF. Evidence of dysfunction of a prefrontal-limbic network in schizophrenia: a magnetic resonance imaging and regional cerebral blood flow study of discordant monozygotic twins. Am. J. Psychiatry 1992;149:890-897. [PubMed: 1609867]

Wilkinson, GS. Wide-Range Achievement Test (WRAT-3) Manual. Wilmington, DE: Wide Range; 1993. 


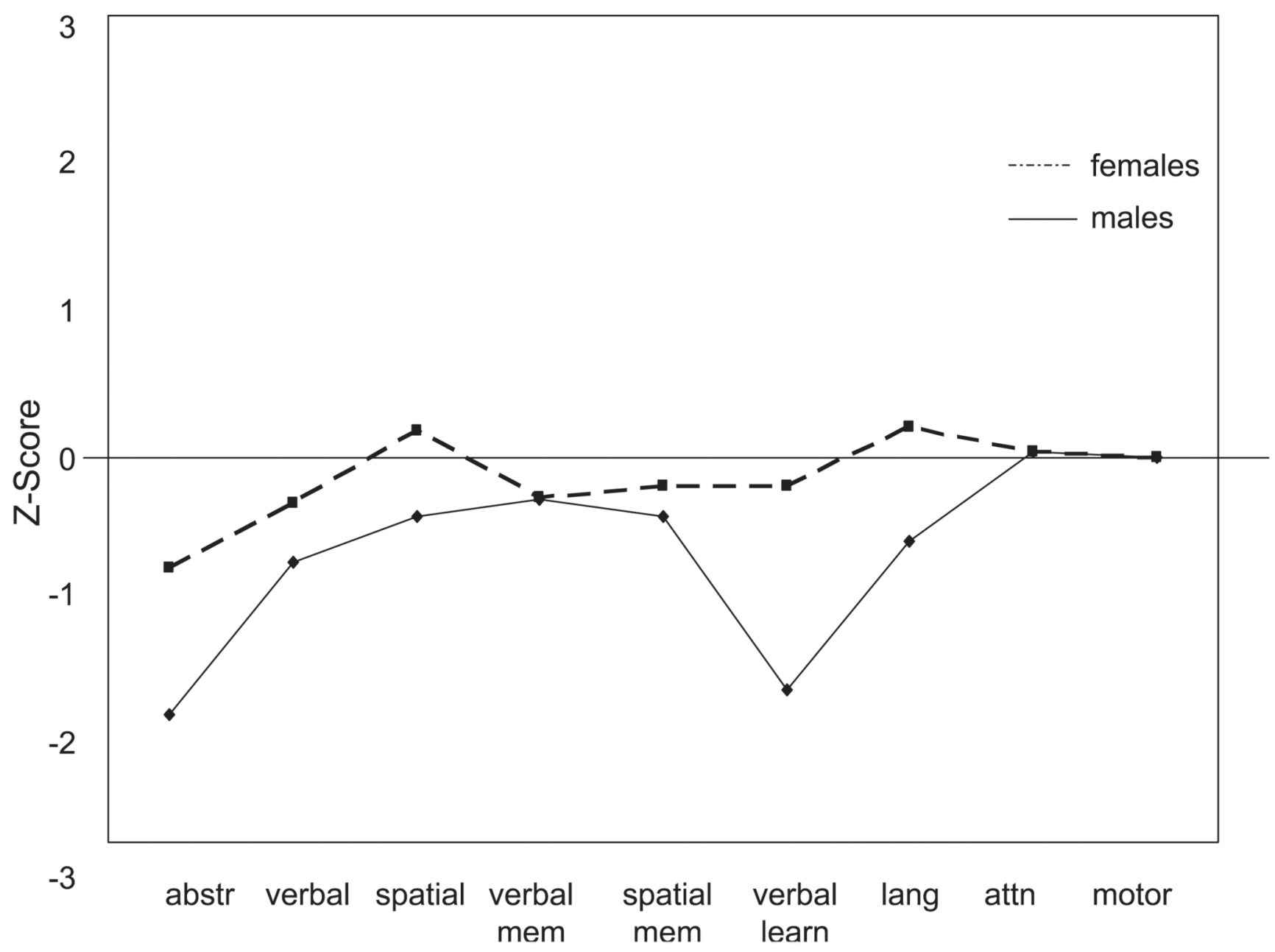

Fig. 1.

Neuropsychological profile for male and female SPD subjects relative to mean values of sexmatched comparison subjects, which are set to 0 ( \pm 1 S.D.). 


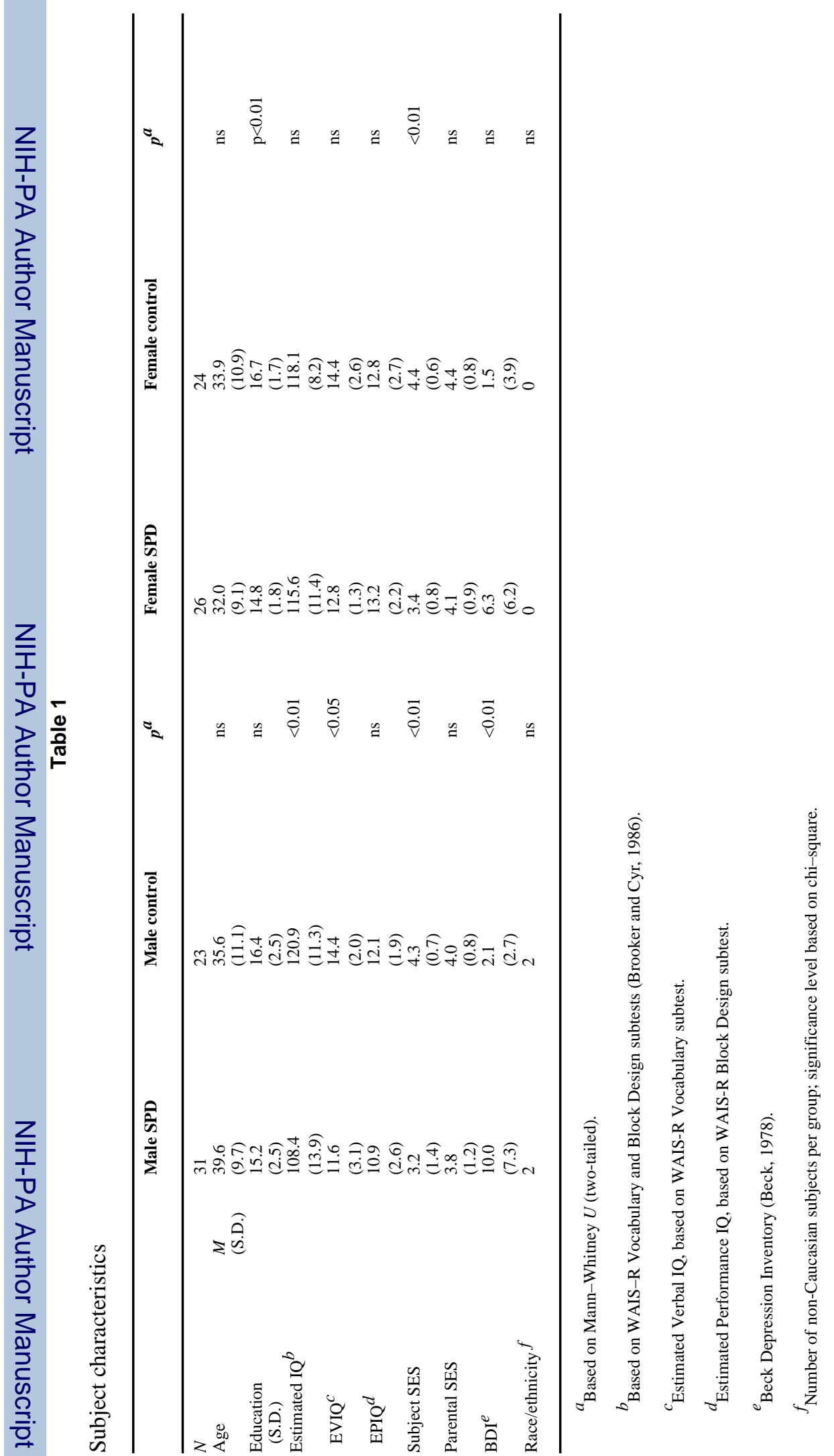


Table 2

Neuropsychological test battery with raw scores

\begin{tabular}{|c|c|c|c|c|}
\hline & Male SPD & Male NC* & Female SPD & Female NC ${ }^{*}$ \\
\hline Abstraction-flexibility (ABSTR) ${ }^{r}$ & -0.042 & -0.871 & -0.939 & -0.861 \\
\hline WCST Categories $M$ (S.D.) & $4.72(1.73)$ & $5.95(0.23)$ & $5.06(2.05)$ & $5.63(1.06)$ \\
\hline WCST Perseverative Responses & $16.59(13.01)$ & $7.21(4.49)$ & $12.69(12.32)$ & $10.54(11.25)$ \\
\hline Verbal intelligence (VERBAL) ${ }^{r}$ & 0.442 & 0.577 & 0.508 & 0.436 \\
\hline WAIS-R Vocabulary & $11.66(2.77)$ & $14.74(2.02)$ & $12.88(2.03)$ & $13.96(1.99)$ \\
\hline WRAT-3 Reading & $103.45(11.11)$ & $112.58(4.03)$ & $108.81(7.93)$ & $113.13(5.12)$ \\
\hline Spatial organization (SPATIAL) ${ }^{r}$ & 0.420 & 0.451 & 0.473 & 0.572 \\
\hline WAIS-R Block Design & $11.03(3.03)$ & $13.26(2.58)$ & $12.44(2.73)$ & $12.21(2.52)$ \\
\hline Judgment of Line Orientation & $26.59(3.41)$ & $27.79(2.53)$ & $25.81(3.83)$ & $25.92(3.69)$ \\
\hline Verbal learning (VLEARN) ${ }^{r}$ & -0.578 & 0.693 & -0.042 & 0.612 \\
\hline CVLT Total correct, trials $1-5$ & $48.07(9.78)$ & $62.05(8.61)$ & $58.44(4.53)$ & $62.21(7.19)$ \\
\hline Language (LANG) ${ }^{r}$ & 0.610 & 0.670 & 0.420 & 0.510 \\
\hline MAE Controlled Oral Word Association & $42.14(14.74)$ & $48.53(9.41)$ & $41.06(10.17)$ & $47.37(11.87)$ \\
\hline BDAE Animal Naming & $23.31(7.41)$ & $28.95(5.81)$ & $26.44(6.14)$ & $27.50(7.87)$ \\
\hline Attention (ATTN) ${ }^{r}$ & 0.292 & 0.331 & -0.198 & -0.104 \\
\hline HRB Trail Making Test (Part B, time) & $69.80(31.02)$ & $52.47(21.22)$ & $62.29(20.05)$ & $49.38(17.63)$ \\
\hline WAIS-R Digit Span & $11.00(3.25)$ & $12.42(2.89)$ & $10.75(2.14)$ & $11.33(2.01)$ \\
\hline Motor skills (MOT) ${ }^{r}$ & 0.710 & 0.774 & 0.608 & 0.640 \\
\hline HRB Finger Tapping Test, right hand & $49.35(9.10)$ & $54.16(5.53)$ & $47.12(7.84)$ & $49.87(5.30)$ \\
\hline Left hand & $43.47(8.23)$ & $49.02(4.12)$ & $41.12(5.77)$ & $43.36(4.80)$ \\
\hline
\end{tabular}

$\stackrel{r}{=}$ Pearson $r$ correlation coefficient, summary statistic per group.

*

* The male and female comparison groups did not differ significantly in neuropsychological test performance in any cognitive domain, except for Finger Tapping Test performance, where males were superior to females, bilaterally.

WCST indicates Wisconsin Card Sort Test (Heaton, 1981); WAIS-R, Wechsler Adult Intelligence Scale-Revised (Wechsler, 1981); HRB, HalsteadReitan Battery (Reitan and Wolfson, 1985); BDAE, Boston Diagnostic Aphasia Examination (Goodglass and Kaplan, 1983); WRAT-3, Wide Range Achievement Test (Wilkinson, 1993); CVLT, California Verbal Learning Test (Delis et al., 1987); MAE, Multilingual Aphasia Examination (Benton and Hamsher, 1978). 